\title{
A música e as suas repercussões nas ordens sociais e mentais
}

\section{Beatriz Licursi $^{a}$, Levi Leonido Silva ${ }^{b}$, Mário Cardoso ${ }^{c}$, Elsa Morgadod}

${ }^{a}$ Universidade Federal do Rio de Janeiro, Rio de Janeiro, Brasil, musicafeliz@terra.com.br, ${ }^{\mathrm{b}} \mathrm{CITAR}$, Porto, Portugal, Universidade de Trás-os-Montes e Alto Douro, Vila real, Portugal, levileon@utad.pt, 'Instituto Politécnico de Bragança, Bragança, Portugal, cardoso@ipb.pt, Centro de Estudos Filosóficos e Humanísticos, Universidade Católica Portuguesa, Braga, Portugal, Universidade de Trás-os-Montes e Alto Douro, Vila Real, Portugal, Instituto Politécnico de Bragança, Bragança, Portugal, levielsa@utad.pt.

\begin{abstract}
Resumo
Foi objetivo geral desse artigo, compreender como a música repercute nas ordens sociais e mentais dos homens. Foi realizada uma revisão de literatura e os dados foram interpretados pelo método qualitativo. Concluiu-se que a música tem grande repercussão na vida social humana, pois os ajuda a manter a capacidade de se conectar com os sistemas emocionais profundos, gerando sentimentos relacionados à capacidade de inter-relações sociais e atividades em equipe. Ouvir música cria estímulos nas áreas do cérebro que são comumente ativadas para entender os sentimentos subjetivos e os pensamentos de outras pessoas.
\end{abstract}

Palavras-chave: Música, Relações Sociais, Repercussões Mentais.

\begin{abstract}
The general objective of this article was to understand how music affects social and mental orders. A literature review was carried out and the data were interpreted by the qualitative method. It was concluded that music has great repercussions on human social life, as it helps human beings to maintain the ability to connect with deep emotional systems, generating feelings related to the capacity for social interrelationships and team activities. Listening to music creates stimuli in areas of the brain that are commonly activated to understand other people's subjective feelings and thoughts.
\end{abstract}

Keywords: Music, Social relationships, Mental repercussions. 


\section{Introdução}

A arte musical é revelada como uma disciplina eminentemente social, uma vez que foi criada ao longo da história, por e para grupos de pessoas que assumem diferentes papéis sociais. O fenômeno musical não é apenas importante por seu valor cultural, mas também por ser um elemento dinâmico que participa da vida social e gera repercussões mentais na mente dos sujeitos. Os especialistas em neurociência têm investigado como e por que a música influencia a mente. Estudos da última década mostram que a música estimula várias regiões do cérebro, incluindo aquelas que envolvem emoções, memória, movimento, tempo e idioma: enquanto a letra de uma música ativa o idioma central na mente, outras áreas do cérebro conectam a música a momentos do passado, como um primeiro beijo ou eventos da infância (Sousa \& Ivenicki, 2018). A música desperta quase todas as áreas do cérebro; o que não parece uma surpresa, pois faz as pessoas moverem os pés ao ritmo da música, promove a conexão interior com as emoções do passado e tem o potencial de modificar o estado mental do sujeito. Estudos indicam que o ato de ouvir música ativa mais partes do cérebro do que qualquer outro tipo de estímulo conhecido (Silva, 2014). Nesse cenário, esse estudo se justifica, pois visa compreender como a música influencia a mente humana e como ela interfere no processo de desenvolvimento do sujeito em sociedade. Parte-se do pressuposto que são necessárias mais pesquisas sobre por que e como a música se tornou um fenômeno de mudança e de criação de identidade cultural nas sociedades antigas, acredita-se que com esse entendimento seja possível uma melhor compreensão de quais repercussões mentais e sociais a música possui na sociedade atual.

\section{O papel fundamental da música no desenvolvimento das sociedades humanas}

Para o homem primitivo, havia dois sinais que evidenciavam a separação entre vida e morte: o movimento e o som. Os ritos da vida e da morte se desenvolvem nessa chave dupla. A dança e a música se fundem como símbolos da vida. Quietude e silêncio como símbolos da morte. O homem primitivo encontrou música na natureza e em sua própria voz. Ele também aprendeu a usar objetos rudimentares (ossos, juncos, troncos, conchas) para produzir novos sons. Há evidências de que, cerca de 50 séculos atrás, na Suméria, eles já tinham instrumentos de percussão e cordas (liras e harpas) (Hall, 2003). É muito provável que no século VI a.C., na Mesopotâmia, eles já conheciam as relações numéricas entre os comprimentos das cordas. Essas proporções, 1: 1 (uníssono), 1: 2 (oitava), 2: 3 (quinto) e 3: 4 (quarto), e suas implicações harmônicas foram estudadas por Pitágoras (século IV a.C.) e 
levadas para a Grécia, de onde a teoria musical se espalharia por toda a Europa (Hall, 2005). Na Grécia antiga, a música também abrangia poesia e dança. Sabe-se que tanto a dança quanto o atletismo têm seu acompanhamento musical no tempo de Homero. No início do século $\mathrm{V}$ aC, Atenas se tornou o principal centro de poetas-músicos que criaram um estilo clássico. A partir do século IV a.C., o músico começou a ser considerado mais como artista do que como autor. O resultado foi o nascimento do virtuosismo e o culto aos aplausos. A música, em geral, tornou-se entretenimento, de modo que o músico perdeu muito de seu status social. O ensino musical marcou um grande declínio nas escolas, e os gregos e romanos das classes altas consideraram degradante tocar um instrumento. A divisão entre o cidadão e o profissional causou o divórcio social e artístico que em nossos dias ainda afetam a profissão de música (Sousa \& Ivenicki, 2018). Analisando a música da Antiguidade até os dias de hoje, atesta-se que ela não foi apenas diferenciada por quantidade, mas basicamente por ter levantado novas direções nos comportamentos humanos.

\subsection{A música e a construção da identidade cultural}

Estudos mostram que jovens constroem sua identidade com os figurinos, o penteado, a linguagem, bem como com a apropriação de certos objetos emblemáticos, neste caso, os bens musicais, pelos quais se tornam sujeitos culturais, de acordo com a maneira de entender o mundo e de vivê-lo, de se identificar e se diferenciar (Schafer, 2012). O consumo cultural cria identificação, ditando padrões de comportamento, códigos, formas de aprender, incluindo uma linguagem enraizada nos objetos que consomem. Em suma, um sistema de crenças é estabelecido. Os membros do grupo agem seguindo essas crenças. Nos grupos em que o elemento de coesão é a música, crenças são geradas a partir dela. É ela quem determina a maneira de se vestir, pentear, se mexer, a maneira de falar. Esse conjunto de crenças constrói a identidade desse grupo de pertencimento. Não é por acaso que a população mais jovem, que inicia seus próprios processos de modelagem de identidade, é a que apresenta o mais alto nível de compra de material de fonográfico, pois é necessário possuir uma série de bens culturais para fazer parte da comunidade cultural (Schafer, 2012). Agora, o que leva os indivíduos a adotarem essas crenças em comum? Qual é a ameaça que eles enfrentam e o que resulta nesse "acordo" de crenças? Talvez seja a intenção de ser alguém nesta sociedade de massa. Em um mundo que tende a extrema homogeneidade, a música parece ser a última saída para mostrar a diferença. Seja original, independente ou rebelde. Talvez seja procurar uma identidade diferente a de seus pais, ou talvez apenas ocupar seu tempo livre, ou abafar a sensação de solidão. O fato é que uma das atividades que a maioria dos adolescentes faz é ouvir música. A música une indivíduos de diferentes pontos da sociedade. De um neohippie belga com piercing no nariz a um dançarino de break em Tóquio, com tranças rasta e jeans largos. Pessoas que não estão próximas no 
espaço social podem, assim, conhecer e interagir, pelo menos brevemente, tendo algo em comum. Música é ao mesmo tempo estilo de vida, vínculo social e força espiritual. A música orienta os sujeitos na busca de autonomia e fornece-lhes meios de expressão (Lima, 2015).

Isso não é ignorado pelas gravadoras, que têm um mercado claro, principalmente os jovens. Esse tipo de indústria aprendeu que pertencer à nova comunidade de valores culturais envolve necessariamente a posse, o conhecimento e o domínio de bens simbólicos específicos, um dos quais gira em torno da música e de seus produtos. Em muitos países, a participação da indústria da música na economia atinge grandes proporções, tornando-se um pilar importante em várias nações. Por esse motivo, a preocupação em buscar, manter e expandir um mercado consumidor é lógica (Zan, 2001). Nesse processo, conhecer e, por sua vez, moldar, mas também se adaptar às preferências musicais tem um papel essencial nas estratégias das empresas. Para isso, a mídia desempenha um papel muito importante, seja para reforçar essa ideia de que para pertencer, é necessário, também, gerar novos mercados, atribuindo valores diferentes à música que lhe são estranhos. Portanto, a música tem um aspecto sociológico. Ela faz parte da superestrutura cultural, um produto das classes sociais, mas também dos meios de produção.

A sociedade gera música como seu produto cultural. Por sua vez, esse produto modifica a própria sociedade, porque a música agrupa os sujeitos de diferentes maneiras, gerando grupos de membros, produzindo alienação, implantando valores, ideais, espalhando-os, gerando modelos e ídolos, inserindo novos atores sociais, novas crenças são geradas, tudo com a consequente ressignificação da música, formando um ciclo de constante ressignificação. Os meios de produção também o fazem, e não apenas com a música, mas a sociedade é moldada para consumir determinados produtos, outros os consideram de baixa qualidade. A indústria fonográfica faz parte dos meios de produção. E, portanto, a música é a matéria-prima com a qual eles trabalham.

A música pode afetar os meios de produção, assim como a estrutura social? Só é preciso lembrar a luta das grandes gravadoras contra a pirataria na Internet. E embora, nesse aspecto, outros fatores intervenham, como sistemas de computadores, o produto comercializável seja a música, e é isso que faz as gravadoras tremerem, enquanto as vendas continuam a diminuir gradualmente (Contier, 2015).

A música também produz um impacto na mente humana. Ou seja, não apenas produz mudanças nos comportamentos do homem e na sociedade, mas também mudanças internas. Por que a música atrai o sujeito? Para responder a essa pergunta, é necessário primeiro definir que tipo de impacto a música é, para onde aponta a memória genética, valores, julgamentos ou opinião. Certamente, na memória genética, deve haver um lugar para a música. Assim como o fogo convoca, é possível que a música também tenha algum efeito 
semelhante. Se assim fosse, toda a estrutura psicológica interna seria modificada, porque se a memória genética e os impulsos primários fossem os pontos mais estáveis, eles modificariam todos os outros segmentos e verificaria se a música tem uma influência muito alta na vida humana. Agora, se a música pretende impactar os valores, o efeito seria menor, embora também fosse de grande importância (Lima, 2015).

Como esses valores são profundamente formativos, certamente seriam muito mais importantes em tenra idade, onde a música poderia determinar a ideia de bem e mal, honra, moralidade, e esses valores permanecem implantados no indivíduo. Então, se o tema da música fosse direcionado a esses valores, certamente haveria uma identificação pelo indivíduo, com o consequente reforço deles. A música também pode impactar os julgamentos, e é provável que seja assim, uma vez que os julgamentos são adquiridos e culturais e, portanto, seu efeito sobre o indivíduo seria menor. Ou simplesmente produza opiniões nas pessoas. Parece que neste caso a influência da música nos indivíduos poderia ser explicada dizendo-se que atinge a parte mais profunda da mente humana (Levitin, 2010).

\subsection{A música como meio de convergência e ressonância da informação no mundo atual}

A indústria da música evolui em um ritmo bastante rápido. A cada ano que passa, vemos como novas plataformas e mídias alcançam fama, estabelecendo seu lugar na indústria e mudando a maneira como o público se conecta com a música e com os artistas (Rausini, Gelinski, Ferreira, \& Sousa, 2018). Ao mesmo tempo, estão surgindo novas tecnologias que oferecem mais ferramentas para pessoas que antes não tinham acesso a elas. Tentar prever o futuro da influência da música em um ambiente tão dinâmico é complicado. $\mathrm{O}$ desenvolvimento da inteligência artificial automatizará o processo de criação e promoção da música, economizando tempo e custos de produção, eliminando intermediários e democratizando a produção e o acesso às músicas. As ferramentas de inteligência artificial que permitem criar composições juntamente com sínteses de voz mudarão a maneira como a distribuição da música funciona, tornando-a mais fácil e acessível a milhares de músicos em todo o mundo (Pinheiro, Leie, \& Barth, 2014). É uma transição do consumo em massa para a criação em massa. A inteligência artificial proporciona ferramentas mais criativas para criar novas produções musiciais. Nesse sentido, atualmente a tecnologia capacita pessoas que nunca se consideraram "artistas" - para que possam fazer música pela primeira vez com a ajuda da inteligência artificial. Essas tecnologias incluem síntese de voz e a composição fornecida pela Inteligência Artificial que permitirá que as pessoas passem do mundo da criação para a distribuição e monetização em tempo recorde. Em resumo, a tendência aqui é a crescente democratização da criação de músicas por meio de software de alta qualidade, disponível em dispositivos móveis a preços baixos ou em navegadores da 
Web, e geralmente inclui assistência com Inteligência Artificial, facilitando a criação de algo que soa bem. A inteligência artificial também tornará mais fácil criar e enviar a mensagem perfeita para o público perfeito no momento perfeito. No lado comercial da música, isso ajudará os artistas a alcançar seu público com mais eficiência, o que gerará mais receita (Rausini et al, 2018).

Tendo visto o que é capaz de fazer em publicidade e marketing, a Inteligência Artificial terá um papel mais importante na perfeição das campanhas publicitárias, oferecendo assim mais lucros aos artistas. Os anunciantes podem aproveitar o poder da inteligência artificial para melhorar e adaptar os anúncios às preferências e gostos dos clientes. Os algoritmos usarão informações do consumidor para exibir anúncios vinculados ao horário, local e usuário específicos, tornando o conteúdo conforme os padrões de consumo. A publicidade personalizada gerará mais retorno do investimento e lucros para os artistas que ajustam as comunicações, de modo a alcançar os melhores públicos no melhor momento (Pinheiro, Leie, \& Barth, 2014).

O conteúdo pode ser recomendado ao usuário, com base no que as pessoas ao seu redor estão ouvindo, com base na proximidade ou dia da semana ou hora do dia. Ou seja, um usuário não pode ouvir o EDM às 7 da manhã de uma quarta-feira, quando está se preparando para ir trabalhar, mas ele já o ouve na sexta à noite. Eles seriam os padrões comportamentais dos usuários. É por isso que cada vez mais publicidade se torna mais inteligente e o conteúdo da publicidade se torna muito melhor e mais relevante (Rausini et al., 2018).

O consumo de música controlada por voz e alto-falantes inteligentes mudará a maneira como consumimos música. Os comandos de voz permitirão que os ouvintes ouçam músicas que se ajustem facilmente às suas preferências, sem precisar interagir com interfaces de texto, além de poderem explorar álbuns ou listas. A atual democratização que impulsiona as tendências de streaming será associada aos mercados locais. Nestes territórios em desenvolvimento, o consumo de música será diferente do que vemos hoje. Esse novo fluxo de usuários de todo o mundo aumentará o foco da indústria na música local. O próximo "bilhão" de consumidores de streaming não virá dos mercados ocidentais ou das cidades urbanas desenvolvidas, mas das áreas rurais da Ásia, África e América Latina, onde há um interesse maior no repertório e no talento local. Os serviços de streaming e registro precisarão reconfigurar suas propostas, estrutura de preços e experiência do usuário para atender a essas diferentes necessidades (como planos de baixo consumo, diferentes níveis tarifários, idiomas regionais e / ou locais, etc.) (Pinheiro, Leie, \& Barth, 2014).

Alguns dos mercados locais sofrerão mudanças repentinas e rápidas alterações devido à complexidade do seu sistema atual. Por exemplo, apesar de quão difícil e complexo é o mercado da música no Japão, com sua língua, sua cultura e todas as suas diferenças, as 
mudanças acontecerão. É inevitável, então a questão é como isso vai acontecer. No Japão, ninguém sabe, mas todo mundo está tentando se posicionar. As listas contextuais mudarão a maneira como descobrem a música, e a música gerativa ou geradora (música criada por algoritmos e sistemas computadorizados) satisfará os consumidores que estavam procurando listas de reprodução com base em seu humor. As pessoas estão usando a música para melhorar seus momentos e dias. Isso nos leva a novas oportunidades e desafios. A música gerada continuará a melhorar cada vez mais à medida que mais empresários e investidores se interessarem neste espaço, vendo uma oportunidade. Aplicativos como o Endel tornaram-se populares no Japão, e especialistas prevêem que outras opções surgirão, por exemplo, aplicativos para meditar que poderiam usar algoritmos gerados para aumentar suas listas de músicas ambientais. As barreiras existentes entre diferentes mídias e indústrias, como música, moda e cinema, agora estão desaparecendo, e essa tendência se acelerará no futuro (Calheiros, 2015). As gravadoras estão investindo mais em documentários sobre seus artistas (como aconteceu com o Bohemian Rhapsody); empresas de videogame estão se juntando a artistas para fazer shows em seus jogos (como aconteceu com a aparição de Marshmello em Fortnite); os grandes artistas estão criando suas próprias marcas de moda (como Rihanna fez com a Fenty); De fato, existem artistas que estão fazendo seus próprios programas de culinária (como no mix com Matt FX). Plataformas como Amazon e Apple não apenas transmitem música, mas também programas de televisão e filmes (que começam a reservar estúdios tradicionais junto com a Netflix). As novas marcas musicais estão quebrando o molde das gravadoras tradicionais, unindo diferentes áreas e disciplinas criativas no mesmo ramo da arte (Pinheiro, Leie, \& Barth, 2014). Gravadoras e produtoras sempre tiveram o poder (ou pelo menos a influência) de tomar decisões artísticas. No entanto, as redes sociais capacitaram os artistas a criar uma identidade pessoal, permitindo que eles se conectassem diretamente com seus fãs sem a necessidade de interferência de uma gravadora. Isso fará com que as gravadoras se encarreguem mais dos aspectos financeiros, enquanto os artistas (e seus gerentes) se concentram na direção artística (Pires \& Reichelt, 2012). A inteligência artificial permitirá que jovens estrelas pop sejam descobertas antes e possa comunicar exatamente o que estão sentindo e dizendo. Isso poderia nos levar a uma nova indústria pop. Essas estrelas também precisarão de gravadoras para obter exposição e gerenciar suas carreiras. Redes sociais e serviços de streaming como Spotify e Pandora tiraram o poder das gravadoras e o devolveram aos artistas. Por esse motivo, os gerentes começarão a trabalhar em mais aspectos da carreira do artista. No novo ecossistema musical, os gerentes aumentarão o escopo de seu trabalho no desenvolvimento de um artista, trabalhando como promotor e diretor artístico adicional (em vez de apenas promover os interesses do artista). Cada vez mais gerentes têm o poder de fazer as coisas diretamente, e isso é algo que os fez perceber que suas operações precisam de um suporte e estrutura sólidos. Ter acesso a esse lado trabalhista e organizacional pode mudar drasticamente a situação financeira de muitos 
artistas (Pereira de Sá, 2003). Em apenas 20 anos, a internet mudou completamente o mundo da música e estamos apenas no início dessa transformação. A democratização e colaboração serão o pão do dia-a-dia: os artistas podem fazer música profissional rapidamente. O streaming continuará a dominar os novos mercados, oferecendo música ilimitada a milhões de pessoas. A tendência da democratização será aprimorada pelos mercados emergentes e não tanto pelos que já estão dominando. Os artistas vão se conectar com novos públicos de diferentes áreas. A música será usada de maneiras mais criativas e únicas. Compreender essas tendências e como elas mudarão a maneira como a música é criada, promovida e consumida é extremamente importante. Este é o contexto em que a indústria da música se desenvolverá - e ter um bom entendimento dessas mudanças é essencial para compreender como esse novo ambiente influenciará o sujeito, a sua identidade e sua cultura (Rausini et al., 2018).

\section{Considerações finais}

A música desempenha um papel importante em todas as sociedades e existe em um grande número de estilos. A música é para todos os tipos de pessoas, independentemente de sexo, idade, posição social, etc. Uma vez que é um meio de expressão, uma arte que deve ser apreciada. Assim como a música é dividida em gêneros, o clima das pessoas também é. Então, uma maneira de expressar esse estado de espírito é através da arte chamada música. Graças à música, pessoas formam seu modo de pensar e sua ideologia de vida e sua identidade cultural. Esse processo ocorre, pois ela é capaz de evocar emoções de uma maneira poderosa. Isso é intrigante, uma vez que a música, diferentemente de outros estímulos capazes de evocar emoções, como cheiros, sabores ou expressões faciais, não possui, pelo menos obviamente, um valor biológico ou de sobrevivência intrínseco. Esse estudo sugere a realização de estudos aprofundados que possam aferir as correlações neurais das respostas emocionais à música, relacionando os aspectos da percepção musical ou com outras formas de emoção.

\section{Referências}

Calheiros, E. (2015). Mercado Fonográfico mundial e brasileiro 2015. Disponível em : https://www.pro-musicabr.org.br/wpcontent/uploads/2016/04/MERCADO FONOGRAFICO BRASILEIRO E MUNDIAL $2015 \mathrm{~F}$ INAL_PDFSITE.pdf

Contier, A. (2015). Música e ideologia no Brasil. São Paulo: Novas Metas.

Hall, S.(2005). A identidade cultural na pós-modernidade. Rio de janeiro: dp\&a.

Hall, S. (2003). Da diáspora: identidades e mediações culturais. Belo Horizonte: Editora da UFMG. 
Levitin, D. J. (2010). A música no seu cérebro: a ciência de uma obsessão humana. Rio de Janeiro: Civilização brasileira.

Lima, L. C. (org.) (2015). Teoria da cultura de massas. Rio de Janeiro: Paz e Terra.

Pinheiro, C., Leie, L., \& Barth, M. (2014). A indústria da música como promotora de entretenimento. Revista Temática, 10(1), 3-10.

Pires, D., \& Reichelt, V. (2012). O novo paradigma do mercado fonográfico e a mudança no core business dos principais stakeholders desta indústria. XXXVI Encontro da ANPAD. Rio de Janeiro, 2012.

Pereira de Sá, S. A (2006). A nova ordem musical: notas sobre a noção de "crise" da indústria fonográfica e a reconfiguração dos padrões de consumo. Niterói: UFF - PPGCOM.

Rausini, A., Gelinski, L., Ferreira, M., \& Souza, M.W. (2018). Indústria fonográfica: análise de crescimento pós streaming. Cadernos de Iniciação científica, 3(1).

Schafer, R. M. (2012). O ouvido pensante. São Paulo: UNESP.

Silva, T. T. (2009). Documentos de Identidade: Uma introdução as teorias do Currículo. Belo Horizonte: Autentica.

Silva, T. T. (2014). A produção social da identidade e diferença. In T. T. Silva (org.), Identidade e diferença: A perspectiva dos Estudos Culturais. Petrópolis: Vozes.

Sousa, R. S. de, \& Ivenicki, A. (2018). Cultura, currículo e identidade (cultural): conceitos-base para uma educação musical multicultural. OuvirOUver, 14(2), 438-450. doi : 10.14393/OUV23v14n2a2018-13

Zan, J. R. (2001) Música popular brasileira, indústria cultural e identidade. EccoS Revista Científica, 3(1), 105-122. 